\title{
Sistem Pemasaran Ikan Cakalang di Tempat Pelelangan Ikan TPI Desa Katialada Provinsi Gorontalo
}

\author{
Lis M. Yapanto, Arfiani Rizki Paramata,Tanti H Gumulu \\ lizrossler@ung.ac.id \\ Program Studi Manajemen Sumberdaya Perairan, Fakultas Perikanan dan Ilmu \\ Kelautan, Universitas Negeri Gorontalo \\ Received: 18 Februari 2021; Revised: 26 Maret 2021; Accepted: 28 April 2021 \\ DOI: http://dx.doi.org/10.37905/aksara.7.2.233-238.2021
}

\begin{abstract}
ABSTRAK
Penelitian ini bertujuan untuk (1) Mengetahui sistem pemasaran ikan cakalang di Tempat Pelelangan Ikan (TPI) Desa Katialada Kecamatan Kwandang Kabupaten Gorontalo Utara dan (2) Mengetahui margin pemasaran dan efesiensi pemasaran ikan cakalang di Tempat Pelelangan Ikan (TPI) Desa Katialada Kecamatan Kwandang Kabupaten Gorontalo Utara. Metode penelitian yang digunakan adalah metode deskriptif. Data primer dan data sekunder yang telah dikumpulkan disajikan dalam bentuk bagan dan tabel. Teknik pengumpulan data dilakukan dengan wawancara dan observasi. Populasi dalam penelitian ini berjumlah 67 orang dengan metode penarikan sampel yakni total sampling. Hasil penelitian disimpulkan bahwa Pemasaran hasil tangkapan ikan cakalang di Tempat Pelelangan Ikan (TPI) di Desa Katialada Desa memiliki sistem pemasaran dari nelayan ke pedagang pengumpul ke pedagang besar ke pedagang pengecer dan ke konsumen. Margin pemasaran ikan cakalang di TPI Katialada Kecamatan Kwandang Kabupatgen Gorontalo Utara sebesar Rp. 2.500 sedangkan tingkat efisiensi pemasaran adalah 4,2\% <5\% dengan kategori efisien.

Kata Kunci :Sistem Pemasaran, Ikan Cakalang

ABSTRACT

This study aims to (1) Know the skipjack fish marketing system at the Fish Auction Place (TPI), Katialada Village, Kwandang District, North Gorontalo District and (2) Know the marketing margins and marketing efficiency of skipjack tuna at the Fish Auction Place (TPI), Katialada Village, Kwandang District, Regency North Gorontalo. The method used is descriptive method. Primary data and secondary data that have been collected are presented in charts and tables. The data collection technique was done by interview and observation. The population in this study amounted to 67 people with a sampling method that is total sampling. The results of the study concluded that the marketing of skipjack tuna catches at the Fish Auction Place (TPI) in Katialada Desa has a marketing system from fishermen to collectors to wholesalers to retailers and to consumers. The marketing margin for skipjack tuna at TPI Katialada, Kwandang District, North Gorontalo District is Rp. 2,500 while the level of marketing efficiency is $4.2 \%<5 \%$ in the efficient category. Keywords: Marketing System, Skipjack Fish
\end{abstract}




\section{PENDAHULUAN}

Kabupaten Gorontalo Utara merupakan salah satu Kabupaten yang memiliki perairan laut yang sangat potensial. Kondisi tersebut disadari memiliki potensi wilayah pesisir dan kelautan yang sangat besar, karenannya diperlukan reorientasi serta penyesuaian fokus pembangunan daerah pada sumberdaya perikanan dan kelautan khususnya perikanan tangkap. Tempat Pelelangan Ikan (TPI) Katialada merupakan salah satu pusat pemasaran dan perindustrian hasil tangkapan ikan di wilayah Gorontalo Utara.Tempat Pelelangan Ikan (TPI) Katialada Kwandang merupakan salah satu tempat yang mempunyai potensi produksi dan pemasaran hasil tangkapan ikan yang cukup besar dan strategis. Selain potensi produksi yang cukup besar, Tempat Pelelangan Ikan (TPI) ini juga memiliki potensi pemasaran yang cukup baik karena jumlah penduduknya sangat banyak dan di dukung dengan sarana yang memadai (Profil Tempat Pelelangan Ikan (TPI) Katialada, 2019). Dalam Undang-Undang RI No 31 Tahun 2004 tentang perikanan dijelaskan bahwa salah satu fungsi dari pelabuhan perikanan adalah sebagai pusat pemasaran dan perindustrian hasil tangkapan. Dengan demikian untuk menjalankan fungsi tersebut, pelabuhan perikanan memerlukan dukungan fasillitas pemasaran dan perindustrian yang memadai sehingga pemasaran hasil tangkapan dapat berjalan dengan lancar serta dapat dikembangkan. Fungsi pelabuhan perikanan dapat ditinjau dari berbagai kepentingan, salah satunya sebagai fungsi komersil. Fungsi ini timbul karena pelabuhan perikanan sebagai tempat awal utnuk mempersiapkan pendistribusian produksi ikan melalui transaksi pelelangan ikan (Akbar, 2012).

\section{METODE PENELITIAN}

Penelitian ini dilaksanakan pada bulan Januari - Februari 2020 di Desa Katialada Kecamatan Kwandang Kabupaten Gorontalo Utara.

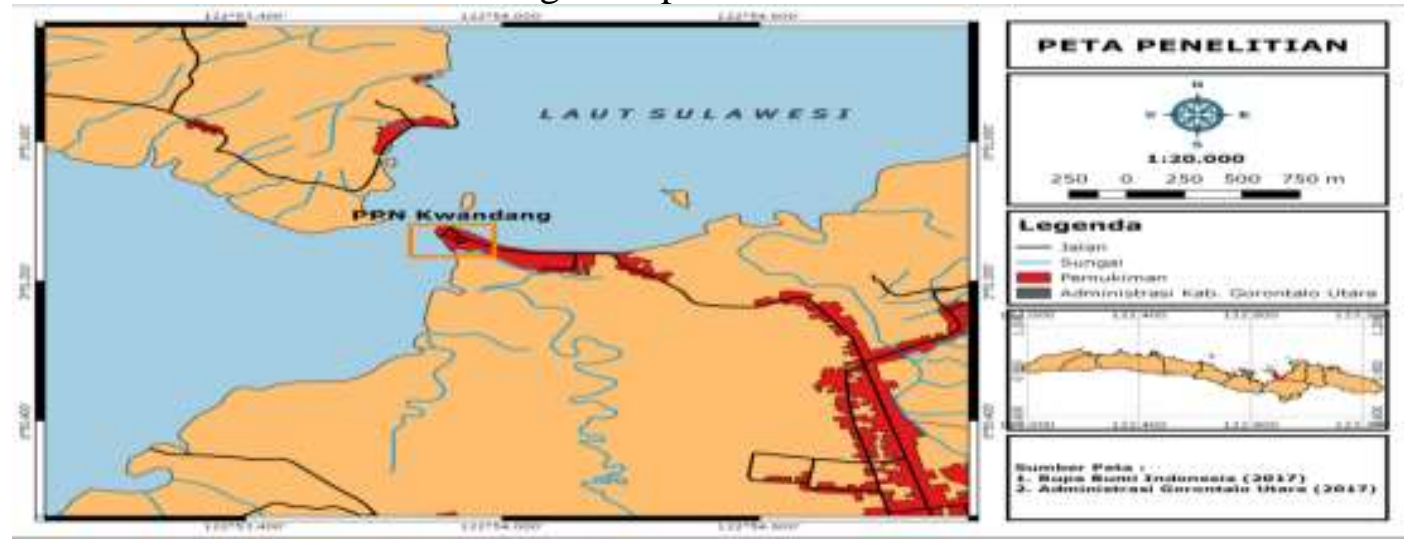

Gambar 1. Peta Lokasi Tempat Pelelangan Ikan Kwandang

Metode penelitian yang digunakan adalah analisis deskriptif terhadap sistem pemasaran ikan cakalang. Data primer dan data sekunder yang telah dikumpulkan disajikan dalam bentuk bagan dan tabel. Data primer dalam penelitian ini berupa hasil wawancara dengan informan dan data sekunder berupa data-data dokumen yang didapatkan dari lokasi penelitian. Prosedur penelitian ini diawali dengan meminta persetujuan untuk pengumpulan data dari TPI desa Katialada dan kemudian menghubungi informan atau responden untuk melakukan wawancara 
tentang sistem pemasaran ikan cakalang.Hal ini dinamakan jenis data yang dibagi menjadi data primer dan data sekunder. Data primer diperoleh dari wawancara sedangkan data sekunder adalah data yang diperoleh dari sumber lain yang sudah ada sebelumnya dan diolah kemudian disajikan. Prosedur pengumpulan data penelitian ini adalah sebagai berikut : 1) Wawancara. Wawancara merupakan teknik yang digunakan untuk mewawancarai informan atau responden yang berhubungan dengan sistem pemasaran ikan cakalang di TPI Katialada Kwandang. Wawancara ini dilakukan secara perseorangan untuk mendapatkan data yang akurat dengan informan atau responden seperti ketua dan staf TPI Katialada, produsen, pedagang besar, pengecer dan konsumen. 2). Observasi. Teknik pengumpulan data ini digunakan dengan cara melakukan pengamatan terhadap keadaan lokasi penelitian dalam hal ini sistem pemasaran ikan cakalang di TPI Katialada Kecamatan Kwandang Kabupaten Gorontalo Utara. Respondenpada penelitian ini sebanyak 67 orang ini terdiri atas 40 orang nelayan, pedagang pengumpul 10 orang dan pedagang pengecer 17 orang. Tehnik pengambilan sampel dilakukan dengan cara menggunakan kuesioner dan wawancara langsung dengan para pedagang. Data yang telah dikumpulkan dari observasi dilapangan, selanjutnya diolah dan di analisis secara deskriptif kuantitatif (Aprilia,2011). Pengambilan data meliputi harga ikan yang dijual, besar pengambilan keutungan, tingkat kenaikan harga di setiap pedagang, serta biaya produksi yang dikeluarkan oleh setiap pedagang. Menurut Hapsari (2013), untuk mengetahui jumlah margin pemasaran ikan diperlukan data seperti harga ikan, saluran pemasaran ikan, biaya produksi pada pedagang pengumpul dan pedagang pengecer. Setelah ditemukan alur pemasaran termasuk jumlah pedagang dan besarnya margin yang terjadi, maka akan didapatkan tingkat efisien dari pemasaran ikan yang berasal dari Tempat Pelelangan Ikan Kwandang.

Menuurt Hapsari (2013), untuk mengetahui tingkat efisiensi pemasaran ikan menggunakan rumus sebahgai berikut:

Eps $=\frac{B p}{H E} \times 100 \%$

Dimana:

Eps:efisiensi pemasaran

Bp:biaya pemasaran

HE:harga eceran

Kriteria:

Eps $<5 \%$ berarti efisien

Eps $>5 \%$ berarti tidak efisien

Margin pemasaran adalah perbedaan harga antara yang harus dibayar kepada penjual pertama dan harga yang dibayar oleh pembeli terakhir. Menurut Oktariza (1996), untuk menghitung margin pemasaran dapat menggunakan rumus sebagai berikut :

$$
\mathrm{MP}=\mathrm{Pr}-\mathrm{HP}
$$

Dimana:

MP: margin pemasaran

Pr: harga di tingkat pengecer

HP: harga di tingkat nelayan 


\section{HASIL PENELITIAN}

\section{A. HASIL PENELITIAN}

Tempat pelelangan ikan (TPI) Kwandang terletak diperairan teluk kwandang yang berhadapan dengan laut Sulawesi pada koordinat 00 51'12" LU $122^{\circ} 53$ '54" BT di Desa Katialada Kecamatan Kwandang Kabupaten Gorontalo Utara Provinsi Gorontalo. Jarak tempat pelelangan ikan (TPI). Kwandang ke Bandar Udara Djalaluddin Gorontalo \pm 36 km dengan waktu ditempuh \pm 45 menit.

\section{Tingkat usia responden}

Tingkat usia reponden dalam penelitian di tempat pelelangan ikan (TPI) berkisar antara 17 tahun sampai 80 tahun. Berdasarkan klasifikasi yang dilakukan sebagian besar responden nelayan berada pada kisaran golongan umur 26 tahun sampai 45 tahun yang mencapai sekitar 99\% (66) orang.

\begin{tabular}{llll}
\hline Kelas & Umur & Jumlah orang & Presentase \\
\hline Remaja & $17-25$ & 0 & $0 \%$ \\
\hline Dewasa & $26-45$ & 66 & $99 \%$ \\
\hline Lansia & $46-65$ & 1 & $10 \%$ \\
\hline Manula & $66-80$ & 0 & $0 \%$ \\
\hline Jumlah & 67 & & $100 \%$
\end{tabular}

\section{Tingkat pendidikan responden}

Tingkat pendidikan responden di Tempat Pelelangan Ikan (TPI) di Desa Katialadayakni sebagian besar menempuh pendidikan sampai tingkat Sekolah Dasar (SD) berkisar 63\% (42 orang). Dari sebagian responden merupakan yang mengikuti pendidikan Sekolah Menengah Pertama (SMP) sekitar 37\% (25 orang).

\begin{tabular}{lll}
\hline Pendidikan & Jumlah & Presentase \\
\hline Tidak Sekolah & 0 & 0 \\
\hline SD & 42 & $63 \%$ \\
\hline SMP & 25 & $37 \%$ \\
\hline SMA & 0 & $0 \%$ \\
\hline SI & 0 & $0 \%$ \\
\hline Jumlah & 67 & $100 \%$
\end{tabular}

Sistem Pemasaran Ikan Cakalang di Tempat Pelelangan Ikan (TPI) Desa Katialada Kecamatan Kwandang Kabupaten Gorontalo Utara

Setelah ikan berada di pelabuhan Tempat Pelelangan Ikan (TPI) di Desa Katialada kemudian dibeli oleh pedagang pengumpul kemudian di jual kepada pedagang besar dan dari pedagang besar dibeli oleh pedagang pengecer yang menjual ikan dalam jumlah kecil kemudian dibeli oleh konsumen.

Dari data di atas menunjukkan bahwa saluran pemasaran yang dilaksanakan di TPI Katialada adalah saluran pemasaran tidak langsung yakni dari nelayan tidak langsung dijual ke konsumen akhir. Namun dari nelayan maka ikan harus masuk ke TPI dan dilakukan transaksi seperti lelang kepada para pedagang pengumpul dan kemudian ke pedagang besar dan pedagang pengecer yang nantinya akan menjual ke konsumen. 


\section{Margin Pemasaran dan Efesiensi Pemasaran Ikan Cakalang Di Tempat Pelelangan Ikan (TPI) Desa Katialada Kecamatan Kwandang Kabupaten Gorontalo Utara}

\begin{tabular}{llll}
\hline Jalur & $\begin{array}{l}\text { Nelayan } \\
\text { (Rupiah) }\end{array}$ & $\begin{array}{l}\text { Pengumpul } \\
\text { (Rupiah) }\end{array}$ & $\begin{array}{l}\text { Pengecer } \\
\text { (Rupiah) }\end{array}$ \\
\hline Harga beli & 13.979 & 14.000 & 14.412 \\
\hline Harga jual & 16.021 & 16.929 & 16.941 \\
\hline Margin pemasaran & 2.042 & 2.929 & 2.529 \\
\hline Biaya pemasaran & 327950 & 1072430 & 1690909 \\
\hline
\end{tabular}

Data margin pemasaran didapatkan dari nilai harga di tingkat pengecer dan harga di tingkat nelayan. Pada jalur I, pelaku yang terlibat yaitu nelayan, Harga beli ikan cakalang pada tingkat nelayan yaitu rata-rata Rp.13.979/kg sedangkan harga jual ikan pada tingkat nelyan rata-rata sebesar Rp16.021/kg.Pada jalur II, pelaku yang terlibat yaitu pedangang pengumpul, harga jual ikan cakalang pada tingkat pedagang pengumpul rata-rata yaitu Rp. $16.929 / \mathrm{kg}$, sedangkan harga beli ikan pada tingkat pedaganag pengumpul rata-rata sebesar Rp 14.000/kg. Pada jalur III, pelaku yang terlibat yaitu pedagang pengecer. Harga beli ikan cakalang pada tingkat pedagang pengecer rata-ratayaitu Rp. $14.412 / \mathrm{kg}$, sedangkan harga jual ikan pada tingkat pedagang pengecer rata-rata sebesar Rp 16.941/kg.

Menurut Widiatuti (2014), efisiensi pemasaran dapat dilihat dari panjanag atau pendeknya distribusi barang dimana semakin panjang rantai pemasarannya maka semakin tidak efisien.

\begin{tabular}{lllll}
\hline Jalur pemasaran & $\begin{array}{l}\text { Biaya } \\
\text { Pemasaran } \\
(\mathrm{Rp})\end{array}$ & $\begin{array}{l}\text { Harga Eceran } \\
(\mathrm{Rp})\end{array}$ & $\begin{array}{l}\text { Efisiensi } \\
(\%)\end{array}$ & Ket \\
\hline Nelayan & 327950 & 15925 & 2,06 & Efisien \\
\hline $\begin{array}{l}\text { Pedagang } \\
\text { Pengumpul }\end{array}$ & 1072430 & 26000 & 4,11 & Efisien \\
\hline $\begin{array}{l}\text { Pedagang } \\
\text { Pengecer }\end{array}$ & 1690909 & 36176 & 4,69 & Efisien \\
\hline
\end{tabular}

Berdasarkan data pada tabel di atas menunjukkan bahwa pemasaran ikan cakalang dari nelayan $2,06 \%$, pedagang pengumpul $4,11 \%$ dan pedagang pengecer 4,69\%. Dari data ini menunjukkan bahwa nelayan tidak mengetahui secara pasti naik turunnya harga Ikan, sementara pedagang pengumpul mendapatkan informasi yang lebih cepat dari lembaga pemasaran lain. Keterbatasan informasi pasar ini terkait dengan letak lokasi mata pencaharian mereka yang berada di daerah pesisir pantai. Hasil penelitian di atas sejalan dengan penelitan yang telah dilakukan oleh Akbar (2012) bahwa salah satu fungsi pelabuhan perikanan adalah sebagai fungsi komersil. Fungsi ini timbul karena pelabuhan perikanan sebagai tempat awal untuk mempersiapkan pendistribusian produksi ikan melalui transaksi pelelangan ikan. Sedangkan menurut Azzaino (2011) bahwa panjang-pendeknya saluran pemasaran yang harus dilalui oleh suatu hasil perikanan dipengaruhi oleh faktor jarak antara produsen dan konsumen. Makin jauh jarak antara produsen dengan konsumen maka makin panjang saluran yang ditempuh oleh produk. 


\section{PENUTUP}

Berdasarkan hasil penelitian dan pembahasan maka peneliti menetapkan kesimpulan sebagai berikut. 1. Sistem pemasaran ikan cakalang di Tempat Pelelangan Ikan (TPI) di Desa Katialadayakni dari nelayan ke pedagang pengumpul ke pedagang besar ke pedagang pengecer dan ke konsumen. 2. Margin pemasaran ikan cakalang di TPI Katialada Kecamatan Kwandang Kabupaten Gorontalo Utara sebesar Rp. 2.042sedangkan tingkat efisiensi pemasaran adalah 2,06 \% $<\%$ dengan kategori efisien. Saran: 1. Pemerintah Desa Tempat Pelelangan Ikan (TPI) di Desa Katialada dapat memanfaatkan Tempat Pelelangan Ikan (TPI) di Desa Katialada bukan hanya sebagai tempat penpemasaranan ikan namun pemasaran ikan terbesar di wilayah Gorontalo. 2. Peneliti selanjutnya dapat memanfaatkan hasil penelitian ini sebagai referensi tentang penpemasaranan hasil tangkapan ikan cakalang dengan mengambil pemasaran jenis ikan lainnya.

\section{DAFTAR PUSTAKA}

Akbar, S. 2012. Pemilihan Lokasi Budidaya. Departemen Kelautan DanPerikanan. Direktoral Jendral Perikanan Budidaya Balai Budidaya Lampung Hal 8.12.https://repository.ipb.ac.id. 6 Des ember 2019 (10.12).

Hanafiah A.M, dan Saefuddin 2013. Sistem Pemasaran dan Margin. PT. RajaGrafindo Persada.

Handoko, 2012. Manajemen Pemasaran. Jakarta. Rineka Cipta. 10 Desember 2019 (13.00) .

Hapsari, TD. 2013. pemasaran Distribusi dan margin hasil tangkapan ikan tongkol (Euthynus offinis) di TPI Ujungbatu Jepara. Aquasains (Jurnal Ilmu

Perikanan dan Sumberdaya Perairan). Vol 2:132.138. http://journal.ipb.ac.id.10 Desember 2019 (10.15).

Oktariza W, 1996. Studi Distribusi Pemasaran Hasil Perikanan Laut dari Pelabuhan Ratu, Sukabumi, Jawa Barat. Buletin Ekonomi Perikanan. Vol. 2 (2): 34.43. http://journal.ipb.ac.id/index.php/jtpk/article/view/11924. 8 Des ember 2019 (10.15).

Sugiyono. 2010. Metode Penelitian Kuantitatif, Kuanlitatif dan $R \quad \& D$. Alphabeta.Bandung.Cetakan ke Sepuluh. https://www.google.com/9 Desember 2019 (10.10).

Yapanto, L. M., Salam, A., \& Hamzah, Z. Y. (2020). Tataniaga Dan Margin Pemasaran Ikan Tuna Di Kota Gorontalo (The marketing of Tuna Fish in Gorontalo City) mengetahui efisiensi pemasaran ikan metode survei, menurut Singaribuan menggunakan metode purposive. 2(2), 38-45.

Widiastuti, Nur. Dan M.Harisudin.2013.Saluran Dan Margin PemasaranIkanKabupaten Grobongan. SEPA, 9(2): 231.240. https://www.r esearchgate.net/publication 6 Desember 2019 (11.15).

Olii, A. H., Yapanto, L. M., \& Akili, S. A. (2019). The Efficiency Handline Fishing Gear in Gorontalo Regency, Indonesia. Asian Journal of Fisheries and Aquatic Research, 1-10. https://doi.org/10.9734/ajfar/2019/v4i430061

Yapanto, L. M., Tanipu, F., Paramata, A. R., \& Actors, E. (2020). The Effectiveness Of Fishery Cooperative Institutions. 17(25), 1329-1338. 
